\title{
MESTIZAJE MÁGICO EN LA CIUDAD. INTERCAMBIOS, APROPIACIONES Y RECEPCIONES. EL PROCESO INQUISITORIAL CONTRA MARÍA FLORES «LA LLANA CANDELA», 1699-1709
}

\author{
NATALIA URRA JaQue \\ Universidad Andrés Bello - Chile \\ natalia.urra@unab.cl
}

\section{INTRODUCCIÓN}

$\mathrm{H}$

ace unas décadas, Serge Gruzinski, inspirado en la obra de Peter Sloterdijk, aseguró que la movilización de los sujetos fue uno de los principales procesos sociales experimentados durante la modernidad, pues junto a ellos se intercambiaron artefactos, costumbres, hábitos e incluso ideas. La expansión de los imperios ibéricos provocó un movimiento y un desarrollo ilimitado. El despliegue militar, político y económico generó una serie de descubrimientos y hallazgos que, a su vez, se palparon en nuevos saberes, nuevas conductas y nuevas creencias. Nada, según el historiador francés, contuvo una movilidad apasionante, incesante y constantemente en auge, pues se tradujo en kilómetros de leguas recorridas y mares atravesados, flujos de materiales, envíos de especias y productos exóticos, fundación de ciudades y fortalezas, deportación masiva de hombres y mujeres e incluso un nomadismo ${ }^{2}$ por parte de otros.

1 Este escrito es el resultado preliminar del proyecto «Magia amorosa en los contextos urbanos: emociones y transgresiones ante la Inquisición de Lima, siglos XVII y XVIII» (DI-05-19/JM), financiado por la Universidad Andrés Bello de Chile, durante los años 2019-2021.

2 Durante la colonización hispana, los sujetos nómadas o migrantes fueron aquellos que transformaron las dinámicas sociales establecidas, pues no solo se trasladaban de un lugar geográfico a otro modificando los entornos, sino también alteraban la convivencia de los espacios, pues reformaban las relaciones personales y, a su vez, las enriquecían. Los desencuentros, enfrentamientos, reciprocidades, afinidades e intereses comunes, crearon un mestizaje capaz de abarcar y solventar una nueva identidad inspirada en los intercambios culturales (Gruzinski 2005 y 2007).

Edad de Oro, XXXVIII (2019), pp. 361-373, ISSN: 0212-0429 - ISSNe: 2605-3314

DOI http://doi.org/10.15366/edadoro2019.38.020 
Al mismo tiempo, la circulación y movilidad planetaria, estimulada por los ibéricos, creó un mestizaje vinculado a la circulación de los cuerpos, a las prácticas, a los saberes y a los imaginarios, pues fue una mezcla, una amalgama y un enlace permanente de reacciones y de ajustes no siempre estables, pues constantemente se enfrentaron pensamientos y estilos de vida (Gruzinski 2005). El mismo Gruzinski invita a revisar y a reconsiderar la colonización americana, ya que el mestizaje simboliza una expresión occidental no siempre destructora o normalizadora. En este sentido, no todo fue reemplazado, a veces se mezcló con las imposiciones e incluso se transformó en una asimilación y en una adecuación, es decir, en una negociación constante e ininterrumpida (2007).

Las estrategias políticas y religiosas de los imperios ibéricos (unión Monarquía e Iglesia), provocaron una mezcla entre el rechazo y las opciones y, al mismo tiempo, entre las extirpaciones y los nuevos deberes, por ende, la occidentalización con el mestizaje convivieron inseparablemente. Ambos factores fueron muy determinantes en las mezclas, sin embargo, ni lo político ni lo religioso se limitaron a obedecer, en algunos casos eran estas faltas e inconsecuencias lo que desencadenó un mestizaje capaz de neutralizar o modificar sus orígenes, pero nunca anularlo (Gruzinski 2007).

Nuestra protagonista refleja a cabalidad lo enunciado por Gruzinski, pues fue uno de esos sujetos cuya corporalidad representaba una mezcla o jerarquización étnica y esto, a su vez, le permitía acceder a una serie de tradiciones variadas, distintas y complementarias. En el proceso inquisitorial desarrollado en su contra (1699-1709), María Flores relató un sinfín de prácticas y conocimientos específicos de un mundo indígena e ibérico. Adivinaciones, curaciones, maleficios y hechicerías fueron algunas de las actividades que, tanto testigos como ella misma, confesaron ante los hombres del Santo Oficio. Entre los folios $109 \mathrm{v}$ y $111 \mathrm{r}$ del expediente 5.345, sección Inquisición de Lima, se describen objetos como los rosarios, las cruces, las hojas de coca, el aguardiente, el maíz y las invocaciones a santos, a vírgenes, a Jesucristo y, por supuesto, al demonio. Durante 10 años se enfrentó a un juicio donde expuso las alianzas, los intercambios, las apropiaciones, las recepciones e incluso las movilidades geográficas.

María Flores, «la llana Candela», fue una de las tantas intermediarias sociales que pese a las limitaciones, imposiciones y restricciones sociales o religiosas, provocó un mestizaje enérgico en torno a las prácticas mágicas y, además, fue un agente activo de la occidentalización ${ }^{3}$; su anonimato como sujeto común no

3 Una de las tantas dinámicas de la occidentalización o mundialización ibérica consistió en articular redes humanas que reprodujeran las acciones colectivas y, en algunos casos, individuales de la monarquía católica. Los resultados que cada una de estas generó fue la base de la colonización hispana, ya que los sujetos comunes, con sus historias y dinamismos personales, promovieron 
condicionó en absoluto el reconocimiento que sus pares le otorgaron. Los saberes adquiridos a través de los años como consecuencia de las movilidades geográficas entre Cusco y Lima y, a su vez, las interacciones con sujetos de otras castas o jerarquizaciones étnicas, influyeron en sus prácticas y actividades. Su supuesta desobediencia fue parte de un proceso social en el que las prácticas supersticiosas fueron una de las tantas mezclas, apropiaciones y recepciones que caracterizaron a las sociedades hispano-virreinales americanas (AHN de Lima, Inq., leg. 5.345, n. ${ }^{\circ} 4$, ff. $109 \mathrm{v}-111 \mathrm{r}$ ).

Ahora bien, nuestro trabajo rescatará aquellos diálogos y testimonios que enfaticen la mesticidad de María. Por un lado, hablaremos de su mezcla corporal y cómo esta es el primer condicionante para aprender y fusionar prácticas supersticiosas. Al mismo tiempo, analizaremos las interacciones sociales, ya que de tales diálogos e intercambios nace un nuevo sistema de ritos y creencias en torno a la hechicería. Y, por último, profundizaremos, desde la experiencia de nuestra protagonista y sus testimonios entregados al Santo Oficio, en aquellos sujetos comunes y anónimos que, de una u otra forma, construyeron los cimientos de una sociedad como la hispano-americana, es decir, mestizada y, por supuesto, occidentalizada.

\section{Mestizaje mágico urbano. Entre Cusco y Lima}

La presencia de sujetos foráneos o migrantes en las grandes capitales de los virreinatos americanos, fue una situación constante y bastante común durante la modernidad. En primer lugar, el auge político y social que caracterizó a estos centros urbanos iba unido al desarrollo de las instituciones administrativas de la monarquía católica. La situación limeña no fue distinta ni ajena a lo experimentado por otras capitales de las monarquías europeas. Como la gran mayoría de ellas, evolucionó de un sistema político tardo-medieval, instaurado por los primeros conquistadores, a un sistema cortesano típicamente barroco (Martínez Millán 2015).

Desde su fundación en 1535, Lima acogió entre sus calles a una serie de sujetos nómadas, la gran variedad de etnias y mestizajes corporales fue una de las características más notorias, pues como centro político-administrativo del virreinato peruano presenció el auge y el declive demográfico. Los estudios actuales sobre Lima y su población alardean de que el proceso migratorio no es contemporáneo, ya que desde sus orígenes, como capital virreinal, simbolizó un cambio de estatus social y, por supuesto, económico para muchos personajes que se instalaron en ella. Las

encuentros, intercambios y mediaciones culturales. Nuestra protagonista se trasladaba de Cusco a Lima, aprendió algunos métodos curativos de su padre que, al parecer, era un indio, practicaba algunas supersticiones invocando a santos cristianos y a divinidades incaicas, por lo tanto, con sus actos y conocimientos reforzó antiguas creencias y creó otras nuevas. 
oportunidades que la gran ciudad les ofrecía, también condicionaban las relaciones personales; muchos sujetos buscaban en la ciudad el medio para surgir y dejar atrás estilos de vida no siempre acordes o afines a sus intereses (Estenssoro 2003).

Las estrategias para sobrevivir eran múltiples e incluso distantes del orden imperante; la violencia y las transgresiones, por ejemplo, eran muy comunes; algunos incluso experimentaron la delincuencia, la mendicidad y la ebriedad. Sin embargo, no todos cometían tales infracciones, pese a lo complejo de encontrarlos en los archivos. A veces, la documentación refleja las dinámicas e interacciones de los sujetos populares y estos, a su vez, representan aspectos comunes y generales de una sociedad ${ }^{4}$. Estudiarlos por separado sería un error, ya que tanto unos como otros, es decir, infractores y honrados, formaban parte de una colectividad que, al mismo tiempo, poseía sus propios códigos de sociabilidad. Por ende, no todos eran agravios, insultos o conflictos, a veces existían lazos de amistad y solidaridad (Cosamalón 1999).

En este caso, el mestizaje no solo representó la mezcla de los cuerpos, sino también la pervivencia de las costumbres y las tradiciones distintas a las impuestas por las instituciones y mentalidades del Antiguo Régimen hispano, es decir, el mestizaje transformó las estructuras y los principios políticos e ideológicos, pues simbolizó las diferencias morales, culturales y étnicas de la América hispana. Algunos investigadores como S. Gruzinski y Verena Stolcke sostienen que las relaciones entre vencedores y vencidos fueron parte de este mestizaje, ya que ambos crearon dinámicas de convivencia y, sobre todo, de sobrevivencia. Además, condicionó las relaciones entre hombres y mujeres, ya que la sexualidad posee fuertes simbolismos políticos, los cuales, a su vez, se reproducen y jerarquizan según sus condiciones étnicas, económicas y sociales (Gruzinski 2007; Stolcke 2008).

María, según los datos inquisitoriales, era de origen cusqueño, mestiza, cincuentona e hilandera. No obstante, pese a su categorización o jerarquización étnica, provocó una dinámica social lejos de lo esperado e impuesto por las esferas hegemónicas, ya que por medio de sus acciones vulneró las normativas y las realidades, principalmente aquellas vinculadas a los intercambios y a las apropiaciones, es decir, interactuó recíprocamente con sus pares y con otros grupos étnicos (Mannarelli 1999).

4 La documentación estudiada se limita a describir las transgresiones sociales, religiosas, morales e incluso culturales de algunos sujetos. Sin embargo, son estas desviaciones o incumplimientos de la norma lo que genera una dinámica social activa entre estos supuestos transgresores. La convivencia, buena o mala, positiva o negativa, es la que produce una reacomodación de las interacciones sociales y, sobre todo, de los sujetos con la justicia. María Flores transgrede las estructuras sociales, pues fluctúa distintos espacios que le permiten intercambiar conocimientos $\mathrm{y}$, a su vez, apropiarse de otros. No obstante, son sus desviaciones las que refuerzan la normativa moral y social impuesta por la Corona española. Para Mayor información revisar la obra de Michel Foucault. 
Su expediente detalla algunas alianzas que ejemplifican estas relaciones, especialmente las dinámicas de una sociedad mezclada. En sus primeras declaraciones aseguró descender de indios y mestizos y, al mismo tiempo, cumplir con los mandamientos y las normas de la Iglesia, pues según uno de sus testimonios, fechado el 16 de abril de 1709, confesó ser cristiana bautizada y, a su vez, conocer los misterios de la santísima trinidad, pese a no recordarlos ni estar confirmada. En la misma audiencia, relató su devoción por un santo eccehomo, a quien le encendía luces los miércoles y los viernes, puesto que no quería que el resto de la semana sus gallinas la oyesen. Incluso, en cierta ocasión, se acercaron a su casa tres indios y una india para pedirle que les hiciera un milagro. Estos, desesperados por saber quién les había robado una mula, le entregaron dos pesos para comprar velas y hacer una misa a las ánimas; luego, entre todos bebieron chicha y le bailaron a la imagen. Sin embargo, al culpar a uno de ellos, la calumniaron y la acusaron al juez de los indios, asegurando que María había abofeteado al santo. El juez la envió a la cárcel. Allí recibió azotes y, más tarde, fue encerrada en el beaterio de la macarena (AHN de Lima, Inq., leg. 5.345, n. ${ }^{\circ} 4$, f. 110r-v).

La noticia sobre su reclusión llegó a Lima un 27 de octubre de 1699, es decir, una década antes de su primera audiencia ante el Santo Oficio. Durante los diez años previos, el comisario inquisitorial comenzó a investigar los antecedentes de María. Durante la indagación, corroboró su mesticidad y origen cusqueño. Datos no menores al estudiar su expediente y, sobre todo, su posición frente a sus pares, ya que su aspecto de cincuentona y trabajo de hilandera, provocaron que nuestra protagonista fuera reconocida dentro de su entorno por una serie de sujetos que, además, respaldaron las primeras acusaciones.

Varios años después, cuatro calificadores concluyeron con fecha 27 de febrero de 1707, que nuestra protagonista cometía sortilegios simples y adivinatorios de vana observancia, como también sortilegios hereticales con pacto expreso con el demonio; por lo tanto, era vehemente sospechosa. Sin embargo, por sus blasfemias y apostasía era vehemente sospechosa de herejía e infidelidad judaica. Finalmente, un 11 de julio de 1708, el fiscal votó que María debía ir presa a las cárceles secretas con embargo de bienes, por ende, se envió la orden de traslado al comisario del Cusco y, así pues, llegó a Lima un 8 de febrero de 1709 (AHN de Lima, Inq., leg. 5.345, n. ${ }^{\circ} 4$, f. 110r-v).

Ahora bien, el encuentro y los diálogos entre María y la justicia inquisitorial reflejan las múltiples dinámicas e interacciones típicas de una sociedad mestizada, mezclada y, por supuesto, variada. En primer lugar, sus conocimientos no son representativos de un solo grupo étnico, sino más bien de la gran amalgama que caracteriza a las poblaciones hispano-americanas. Incluso, pese a que la documentación no determina el origen de los testigos, exceptuando a los cuatro primeros, también es posible apreciar la diversidad de creencias de cada uno de ellos 
(Rosellón 2016). En los contextos urbanos, las hechiceras jamás trabajan solas, la mayoría posee un grupo de aliadas que comparten saberes similares y, cuando esto no ocurre los intercambian para beneficiarse a sí mismas o al colectivo. A veces, cuando no pueden solucionar el problema de algún cliente, lo llevan con otra sortílega, quien no siempre pertenece al mismo grupo étnico. Por consiguiente, el entramado de ritos y conjuros deja en evidencia las apropiaciones y las recepciones que existen entre ellas, pues - de una u otra forma - todas utilizan las hojas de coca, el aguardiente, el maíz, los fluidos corporales y, por supuesto, las invocaciones al demonio (Estenssoro 2003).

En su expediente, los testigos aseguraron que María realizaba actos supersticiosos como curar maleficios rezando el credo mientras los dolientes debían quitarse las cruces y los rosarios del cuello. Al mismo tiempo, mascaba hojas de coca y conjuraba a la plata y al oro, pidiendo dinero para encenderle luces a una imagen de nuestra señora y a un santo eccehomo, a quien abofeteaba y tiraba de sus barbas. Además, en cierta oportunidad y a modo de halago, tocó la cabeza de una culebra que estaba a los pies de un crucifijo para luego amenazar de muerte a quienes lo revelasen. De igual modo, adivinaba lo que pasaba en otras regiones, pues era capaz de viajar 200 leguas entre Cusco y Lima en tan solo 24 horas, ya que sabía todo lo que sucedía en la capital virreinal, incluso antes de que llegara el correo ordinario a la ciudad del Cusco.

Por lo tanto, la movilidad geográfica, también es una constante, ya que el traslado de un lugar a otro significa renovar la red de clientas, la red de aliadas $\mathrm{y}$, además, los conocimientos, sin olvidar el anonimato que a veces se requiere para escapar de la justicia y, sobre todo, para adquirir complicidad con otras compañeras y con otros grupos (Tausiet 2007). María, según las testificaciones dadas al Santo Oficio, viajaba de Cusco a Lima para llevar consigo una serie de datos, experiencias y aprendizajes nuevos e incluso desconocidos para su entorno cercano; no obstante, siempre los utilizaba para aumentar su prestigio. Las transgresiones supersticiosas, muchas veces, eran construidas por la misma ortodoxia religiosa. En otras palabras, las limitantes, las prohibiciones y los desconocimientos moldearon las prácticas mágicas y, a su vez, estimularon los intercambios entre sujetos de distintas etnias o jerarquizaciones. Por ende, muchas hechiceras, como nuestra protagonista, se transformaron en intermediarias sociales o en negociadoras culturales (Rosellón 2016; Estenssoro 2003).

En las mismas testificaciones, «la llana Candela» o María Flores, también fue acusada por realizar brebajes amatorios para las mujeres, ya que mezclaba aguardiente con los cabellos masculinos de los hombres a quienes deseaban. Luego invocaba al demonio con el nombre de pichincho y si alguna llevaba rosarios o cruces les pedía que se los quitasen, incluso les advertía que no rezasen el credo en secreto. En más de una ocasión echó a una de ellas, ya que al no cumplir sus 
normas, el hechizo no surtía efecto. Al salir de la habitación donde ejecutaba estas supersticiones, las mujeres la oían hablar con un hombre de voz muy estremecedora y espantosa. De la misma forma, la escucharon hablar con un crucifijo en las puertas de un convento y después de bendecirlo la vieron escupiéndolo. Otro testigo, agregó que a una de sus hijas la castigó porque cantaba y asistía a misa en el beaterio, sin embargo, al pedirle clemencia por todos los diablos dejó de reprenderla (AHN de Lima, Inq., leg. 5.345, n. ${ }^{\circ}$ 4, f. 109r-v).

Las capitales virreinales y, en algunos casos, las zonas fronterizas de los reinos ultramarinos promovieron un mestizaje mágico muy activo e intenso. Las testificaciones contra «la llana Candela» fueron una evidencia o prueba de los intercambios que se generaban en estos espacios geográficos. Por un lado, los centros urbanos profesaban una religiosidad hispana muy popular y, por otro, convivían abiertamente con los cultos y creencias precolombinas. En este caso, la diversidad étnica de los sujetos generó una fascinación, un desprecio e incluso un miedo recíproco entre todos ellos. Sin embargo, independientemente de los sentimientos positivos o negativos que despertaran en el otro, se necesitaban para construir una ritualidad que les diera una identidad americana y, por supuesto, mestizada (Torquemada 2018). Los indios, por ejemplo, fueron la única categoría étnica no juzgada por la Inquisición. No obstante, su presencia en las ciudades era tan notoria que, a veces, simbolizaban una verdadera amenaza, sobre todo, respecto a las creencias religiosas y, por supuesto, mágicas. El traspaso o enseñanza de sus conocimientos a otros grupos significó que, en ocasiones, el Santo Oficio posara sus ojos en ellos y, por tanto, expandiera - disimuladamente - su control a otras jurisdicciones eclesiásticas (Millones 2002).

En sus declaraciones al Santo Oficio, María no explicó si su madre o su padre eran indios; sin embargo, aseguró que este era un cirujano y que, además, le enseñó el arte de curar a través de las hierbas, por ende, en su segunda y tercera audiencia, fechadas un 19 y un 20 de abril de 1709, negó ser una bruja. Según su testimonio, jamás apostató y renegó de la fe católica; por lo tanto, su mala fama la adquirió por reunirse con otras curanderas y adivinas ya difuntas. Si bien afirmó pedir dinero a sus clientes para comprar velas y pagar algunas misas, desmintió haber pactado con el demonio, pero sí tener una imagen de un santo eccehomo y una virgen a la que llamaba Pepita. Semanas más tarde, en una audiencia voluntaria, agregó que muchos de los actos supersticiosos que había realizado, eran para obtener dinero y así pagar las novenas para su santo. No obstante, al preguntarle si estos actos eran buenos o malos, ella respondió que ni lo uno ni lo otro, ya que solo los realizaba para engañar y amenazar a las personas que recurrían a ella (AHN de Lima, Inq., leg. 5.345, n. ${ }^{\circ} 4$, f. 110r-v).

El expediente inquisitorial sobre María Flores nos demuestra que muchos de los intercambios, recepciones y apropiaciones generadas en torno a las prácticas 
mágicas, también fueron métodos de resistencias y adecuaciones respecto a la occidentalización que experimentaron los grupos mestizos o heterogéneos. En este sentido, por medio de las supersticiones, no solo mantuvieron uniones y vínculos personales, sino también alianzas culturales y religiosas (Von Wobeser 2016).

María también curaba a los enfermos, por ende, no solo tenía fama de bruja, sino también de curandera ${ }^{5}$. Los testigos afirmaron que en varias ocasiones mezcló hojas de coca con aguardiente y otras hierbas y, luego, con tales menjunjes refregaba los cuerpos de quienes la buscaban. En esas instancias, le encendía velas a la virgen por los costados y, simultáneamente, le bailaba con huesos y tijeras (AHN de Lima, Inq., leg. 5.345, n. ${ }^{\circ} 4$, f. 109r-v).

Las relaciones y dinámicas urbanas no siempre fueron fáciles o amables, muchos forasteros o visitantes creían que en las ciudades los conflictos podían disimularse fácilmente o incluso eran minoritarios. No obstante, al ser espacios numerosos concentraron un sinfín de actividades políticas y como consecuencia un tipo de hechicería, por lo tanto, los hechiceros, curanderos o supersticiosos no solo fueron perseguidos por realizar actividades mágicas, sino también por representar un peligro para las estructuras administrativas imperantes (Levack 1995).

«La llana Candela» fue uno de esos sujetos doblemente amenazadores, ya que por un lado representaba un estereotipo transgresor distante de la reglamentación impuesta a las categorizaciones étnicas y, por otro, maniobraba conocimientos e instrumentos penalizados por la ortodoxia. Por lo tanto, con sus acciones colocaba en entredicho la normativa social y religiosa del Antiguo Régimen Hispano (Urra 2014).

5 Brujas o hechiceras fue el término popular aplicado a mujeres cuyos conocimientos e instrumentalización de objetos, transgredían la posición social que estas debían ocupar en los espacios públicos, es decir, sus prácticas vulneraban las normas impuestas, sobre todo, aquellas vinculadas a las relaciones e interacciones con los hombres. En la actualidad se utilizan como sinónimo, sin embargo, no siempre simbolizaron lo mismo. Durante los siglos modernos (XV al XVIII), la bruja fue un personaje asociado explícitamente al demonio y a sus prácticas maléficas, ya que pactaba con él a través de un contrato en el cual le ofrecía su alma y su cuerpo a cambio de múltiples beneficios. Asimismo, nunca actuaba sola, ya que según los estudios contemporáneos, inspirados en los tratados demonológicos de los siglos XV y XVI, pertenecía a un grupo o «aquelarre» cuya función era rendirle culto y adoración al diablo en conjunto con otras mujeres. La hechicera, por su parte, invocaba a las deidades y recurría a las fuerzas celestiales y, a veces, demoniacas según lo que quisiera en un momento determinado. Conocía los beneficios de las plantas, las hierbas e interfería en las dinámicas sociales. También mezclaba las tradiciones curativas ancestrales con rezos e invocaciones a santos, santas, vírgenes e incluso llamaba al demonio; los tratadistas o demonólogos las diferenciaban de las brujas, porque a diferencia de estas, carecían de una verdadera organización grupal. Por lo tanto, la mayoría de las mujeres procesadas por la Inquisición, tanto en Europa como en América, fueron reconocidas popularmente como «hechiceras», aunque el término jurídico plasmado en los documentos inquisitoriales fue sortílega y supersticiosa. Para mayor información revisar las obras de las investigadoras María Emma Mannarelli, María Tausiet, María Lara Martínez y María Helena Sánchez Ortega, y la tesis doctoral Mujeres, brujería e Inquisición. Tribunal Inquisitorial de Lima, siglo XVIIII de Natalia Urra Jaque. 
María, finalmente, confesó — bajo juramento - un 22 de julio de 1709, que jamás hizo algo contra la santa fe, es decir, desmintió todas y cada una de las acusaciones en su contra, a excepción de las curaciones que aprendió de su padre. Los inquisidores al preguntarle en qué consistían estas, les respondió que eran ejecutadas para bien de los hombres, ya que por medio de las hojas de coca se curaban de los males y se les enderezaban los cuerpos, además, todos en Cusco la usaban sin afán de contrariar a la santa fe. Sin embargo, los mismos jueces que la interrogaban, le aclararon que tales prácticas eran usadas para envenenar. Por lo tanto, al no reconocer los hechos investigados y tener la opinión de cuatro calificadores, un 27 de septiembre de 1709, un inquisidor, un calificador ordinario y dos consultores votaron que María debía padecer tormento in caput propuom et alienum ad arbitrum, ya que era una sortílega heretical, vehemente sospechosa de herejía e infidelidad judaica con pacto expreso con el demonio (AHN de Lima, Inq., leg. 5.345, n. ${ }^{\circ}$, f. 111 r-v).

Ahora bien, ni el tormento al que fue expuesta provocó que confesara alguno de los hechos por los que fue acusada, incluso antes de ser llevada a la cámara y después de ser amonestada hasta la tercera vuelta, aseguró no sentir culpa ni remordimiento ${ }^{6}$. Finalmente, un 9 de diciembre de 1709 , un inquisidor junto a un calificador ordinario y dos consultores la sentenciaron a abjurar de vehementi. En este caso, debía salir a un auto público de fe en forma de penitente con un sambenito de media aspa e insignia de sortílega. En la misma condena quedó estipulado que debía ser instruida en los misterios de la fe, incluso confesarse y comulgar todos los meses por un año. Además, durante ese mismo periodo debía rezar el rosario todos los días. Asimismo, debía salir por las calles públicas de la ciudad desnuda de la cintura hacia arriba, recibir azotes, sufrir el destierro y, a su vez, ser confinada en un hospital durante cuatro años (AHN de Lima, Inq., leg. 5.345, n. ${ }^{\circ} 4$, f. 111r).

Su sentencia no fue distinta a otros castigos y escarmientos inquisitoriales. Los azotes, el destierro, la vergüenza pública y el confinamiento formaban parte de un método correccional exclusivo para el sexo femenino. Los inquisidores creían que a través de tales castigos corregían las torpezas o las debilidades de las mujeres. María, como tantas otras supersticiosas más, fue vulnerada corporal y psicológicamente, ya que a la tortura sumaron el desarraigo y el control sobre sus actos (Schlau 2008; Torquemada 2000).

6 Cuando se trata del tribunal inquisitorial de Lima, pocos procesos relatan algún método de tortura utilizado para la confesión de las acusadas. María es una de las pocas expuestas a la "cámara» y estirada hasta la tercera vuelta. No obstante, pese al tormento del cuerpo no confesó ni afirmó lo que los inquisidores decían sobre ella. Las consecuencias reales sobre tal situación son complejas y difíciles de analizar, ya que el expediente no describe mayores detalles al respecto. Sin embargo, la rebeldía que demuestra, pese a la tortura, permite reflexionar y cuestionar qué tan subordinada era la posición de las mujeres frente a las cortes judiciales e inquisitoriales. 


\section{Conclusiones}

A modo de conclusiones, podemos reafirmar algunas teorías e hipótesis planteadas a lo largo de este escrito, especialmente aquellas en las que los sujetos comunes y, además, representantes de los grupos heterogéneos, desarrollaron un mestizaje activo en torno a las prácticas mágicas o supersticiosas. En primer lugar, su mesticidad, tanto corporal como cultural, los facultó para intercambiar una serie de conocimientos que, finalmente, dieron origen a un nuevo sistema de creencias y ritualidades.

Asimismo, las recepciones y las apropiaciones mágico-religiosas formaron parte de un proceso de occidentalización característico del periodo moderno, pues no fue casual que en las capitales virreinales o centros más habitados de los reinos ultramarinos, se desarrollaran una serie de prácticas mezcladas. En este caso, la modificación o adecuación experimentada en los centros urbanos fue simultánea a los cambios soportados por las estructuras sociales, culturales, políticas y económicas del Antiguo Régimen hispano.

Nuestra protagonista, por ejemplo, maniobró y utilizó una serie de conocimientos que la catalogaron como una experta en curaciones y adivinaciones, pues su propio mestizaje le permitió acceder a tradiciones indígenas e ibéricas. Su relato ante los inquisidores reflejó la amalgama de creencias e ideologías muchas veces fusionadas y aceptadas por los grupos heterogéneos pero, al mismo tiempo, transgresoras y, por tanto, desestabilizadoras para el orden imperante. María, como tantas otras mujeres más, manipuló los saberes y los conocimientos adquiridos a su conveniencia; por un lado, los aprovechó para ganar prestigio y renombre y, por otro, para perpetuar un dinamismo y una reciprocidad entre sujetos distintos y variados. Sus prácticas, como las de muchos otros sujetos, enriquecieron el mestizaje y, por tanto, las identidades hispano-americanas.

Por último, las prácticas mágicas absorbieron y re-amoldaron un sinfín de tradiciones ibéricas, indígenas e incluso africanas ${ }^{7}$. Por lo tanto, representan como tantas otras experiencias socio-culturales, una occidentalización y un mestizaje propiamente americano.

7 En esta oportunidad no analizamos las prácticas mágicas africanas introducidas en América, puesto que el expediente estudiado no describe tales acciones, pues se centra solo en las prácticas indígenas e hispánicas. Sin embargo, existe una mezcla muy importante con los conocimientos africanos, los mismos expedientes inquisitoriales nos lo demuestran, sobre todo, los de la Nueva Granada, cuyos principales condenados fueron esclavos africanos. Los matices que estos incorporaron crearon una nueva forma de concebir el mundo mágico o supersticioso, pues a la ya conocido se sumaron una serie de ritos y creencias complementarias. Para mayor información revisar la obra de Diana Luz Ceballos Gómez, Luz Maya Restrepo y Pedro Vicente Sosa. 


\section{BiBLIOGRAFÍA}

Archivo Histórico Nacional (AHN), Inquisición de Lima, leg. 5.345, n. ${ }^{\circ}$ 4, ff. 109v- 111r. Ceballos, Diana (2001). «Grupos mágicos y prácticas mágicas en el Nuevo Reino de Granada durante el siglo XVII». Historia Crítica, 22, pp. 51-71.

Cosamalón, Jesús (1999). Indios detrás de la muralla. Lima: Fondo PUCP.

Estenssoro, Juan Carlos (2005). Del Paganismo a la Santidad. La Incorporación de los Indios del Perú al Catolicismo, 1532-1750. Lima: IFEA.

Foucault, Michel (1996). La Vida de los Hombres Infames. Buenos Aires: Altamira.

GRUZINSKI, Serge (2005). «Passeurs y elites católicas en las cuatro partes del mundo. Los inicios ibéricos de la mundialización (1580-1640)». En Scarlett Ophelan Godoy y Carmen Salzar-Soler (eds.), Passeurs, mediadores culturales y agentes de la primera globalización en el mundo ibérico, siglos XVI-XIX. Lima: Riva-Agüero, pp. 13-29.

Gruzinski, Serge (2007). El pensamiento Mestizo. Cultura Amerindia y Civilización del Renacimiento. Barcelona: Paidós.

Lara Martínez, María (2016). Pasaporte de bruja. Volando en escoba, de España a América, en el tiempo de Cervantes. Cuenca: Alderabán.

Levack, Bryan (1995). La caza de brujas en la Europa Moderna. Madrid: Alianza Universidad.

Mannarelli, María (1998). Hechiceras, beatas y expósitas. Mujeres y poder inquisitorial en Lima. Lima: Ediciones del Congreso del Perú.

Martínez Millán, José (2015). «La corte de Madrid y las etiquetas cortesanas como modo de distribución del espacio». En Inmaculada Arias de Saavedra y Miguel López-Guadalupe (eds.), Vida Cotidiana en la Monarquía Hispánica. Tiempos y espacios. Granada: Ediciones Universidad de Granda, pp. 39-58.

MAYA Restrepo, Luz (2005). Brujería y reconstrucción de identidades entre los africanos y sus descendientes en la Nueva Granada, Siglo XVII. Bogotá: Ministerio de Cultura.

Millones, Luis (2002). Las Confesiones de Don Juan Vázquez. Lima: IFEA/PUCP.

Roselló Soberón, Estela (2016). «El Mundo Femenino de las Curanderas Novohispanas». En Alberto Baena y Estela Rosellón (coords.), Mujeres en la Nueva España. Ciudad de México: Universidad Nacional Autónoma de México, pp. 233-249.

Schlau, Stacey (2008). «El cuerpo femenino y la Inquisición Colonial: dos casos Ejemplares». Revista del Programa de Historia de América Latina, I, Primera Sección Vitral Monográfico, ${ }^{\circ}{ }^{\circ}$.

Sosa Llanos, Pedro (2005). Nos los Inquisidores. El Santo Oficio en Venezuela. Caracas: Universidad Central De Venezuela

Stolket, Verena y Alexandre Coello (2008). Identidades ambivalentes en América Latina [siglos XVI-XXI]. Barcelona: Ediciones Bellaterra.

Tausiet, María (2004). Ponzoña en los Ojos. Brujería y Superstición en Aragón en el siglo $X V I$. Madrid: Turner

TAusiet, María (2007). Abracadabra omnipotens. Magia Urbana en Zaragoza en la Edad Moderna. Madrid: Siglo XXI. 
Torquemada, María Jesús (2018). «Una bruja mulata: Documento extra ordinem de la Inquisición mexicana». En María Jesús Zamora Calvo (ed.), Mujeres quebradas. La Inquisición y su violencia hacia la heterodoxia en Nueva España. Madrid/Frankfurt am Main: Iberoamericana/Vervuet, pp. 123-153.

URra JAQUE, Natalia (2012). Mujeres, Brujería e Inquisición. Tribunal Inquisitorial de Lima, siglo XVIII. Pilar Pérez Cantó (dir.) [tesis doctoral]. Madrid: Universidad Autónoma de Madrid <https://repositorio.uam.es/handle/10486/9399> [Consulta: 10/03/2019].

URRA JaQue, Natalia (2015). «Prácticas mágicas e identidad mestiza en el virreinato del Perú, siglo XVIII». En Yéssica González (ed.), Diálogos de historia de Chile. Miradas y alcances de la investigación en Chile con enfoque regional. Temuco: Ediciones Universidad de la Frontera, pp. 66-86.

Von Bosever, Gisela (2016). Apariciones de seres celestiales y demoniacos en la Nueva España. Ciudad de México: Universidad Autónoma de México.

Recibido: 20/05/2019

Aceptado: 23/07/2019 


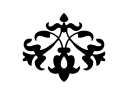

Mestizaje mágico en la CiUdad. Intercambios, apropiaciones y ReCEPCIONES. El proceso inQuisitorial contra María Flores «La llana Candela», 1699-1709

RESUMEN: El siguiente artículo analizará uno de los procesos inquisitoriales desarrollados por el Santo Oficio de Lima entre los años 1699 y 1709. Entre los folios 109v y 111r del expediente 5.345, sección Inquisición de Lima (AHN), se describen las características personales de una mujer cuyos actos, conocimientos e interacciones sociales demuestran las alianzas étnicas, culturales y, sobre todo, supersticiosas en torno a las prácticas mágicas urbanas. Su origen cusqueño, su oficio de hilandera y su calidad de mestiza ejemplifican los intercambios y las apropiaciones de aquellas prácticas y expresiones mágico-religiosas desarrolladas en la ciudad. En cada una de sus confesiones relata a los inquisidores las movilidades, los conocimientos y las habilidades adquiridas a través de los años, pues su calidad de mestiza le permite fluctuar entre los mundos hispano e indígena y, al mismo tiempo, cargar consigo una serie de prejuicios que la facultan para el reconocimiento por parte de sus pares. No obstante, este mismo reconocimiento social la etiqueta como una mujer peligrosa y, por tanto, transgresora. Por consiguiente, detallaremos aquellos diálogos, acciones y expresiones que aseveren las prácticas mágicas urbanas desarrolladas por sujetos cuya posición social simbolizan, por un lado, el intercambio mágico-religioso entre las distintas categorías étnicas y, por otro, una amenaza para las autoridades inquisitoriales.

PAlABRAS ClaVE: mestizaje mágico, prácticas mágicas urbanas, Inquisición de Lima, movilidades geográficas.

\section{Magical MEZTIZAJE IN the CitY: EXCHANGES, ApPROPIATIONS AND RECEPTIONS. \\ THE INQUisitorial TRIAL OF MARÍA FLORES «LA LLANA CANDELA», 1699-1709}

ABSTRACT: This paper analyzes one of the inquisitorial trials conducted by the Santo Oficio of Lima between 1699 and 1709. The pages 109 to 11 of the file 5.345 in the Lima Inquisition section of the AHN describe the personal characteristics of a woman whose knowledge, actions and social interactions reveal ethnic, cultural, and above all superstitious alliances, with urban magical practices. The fact she was from Cuzco, her trade as a spinner, and that she was mestiza exemplified the exchange and appropriations of the magic-religious practices and expressions developed in the city. In each of her confessions, she related to her inquisitors the motilities, the knowledge and the skills acquired over the years, as her being mestiza allowed her move between the Hispanic and indigenous worlds, and, at the same time, carry with her a series of prejudices that facilitated a level of recognition among her peers. However, this same social recognition labelled her as a dangerous woman and, therefore, a transgressor. Therefore, the paper details the dialogues, actions and expressions that assert the urban magical practices developed by subjects whose social position symbolizes, on the one hand, the magic-religious exchange between the different ethnic categories and, on the other, a threat to the inquisitorial authorities.

KEYWORDS: magical meztizaje, acts of urban magic, Inquisition in Lima, geographic motilities. 